\title{
ANALISIS PEMANFAATAN DANAU SENTANI UNTUK PENGEMBANGAN BUDIDAYA KERAMBA JARING APUNG SECARA BERKELANJUTAN
}

\author{
Analysis Development Of Sentani Lake For Development Of Sustainable Floating Net Cage Culture \\ Iman Djuniawal $^{1}$, Suryawati Salam ${ }^{2}$, Sri Mulyani ${ }^{2}$ \\ ${ }^{1}$ Dinas Kelautan dan Perikanan Provinsi Papua \\ ${ }^{2}$ Program Studi Budidaya Perairan Program Pascasarjana Universitas Bosowa \\ Email: imandjuniawal@yahoo.com
}

Diterima : 12 Oktober 2019

Dipublikasikan : 09 Desember 2019

\begin{abstract}
ABSTRAK
Penelitian ini bertujuan untuk menganalisis lingkungan internal dan eksternal yang mempengaruhi pengembangan budidaya ikan dan mengkaji strategi yang tepat dalam usaha pengembangan budidaya ikan karamba Jaring apung di Danau Sentani Jayapura, dilaksanakan selama tiga bulan dari Bulan Juni sampai Agustus 2019. Metode yang dilakukan dengan teknik survei melalui observasi dan wawancara mendalam dengan stakeholder terdiri dari pembudidaya, masyarakat pemanfaat dan pemerintah terkait, dianalisis dengan scoring dan SWOT pada sembilan titik stasiun pengamatan berbeda mewakili areal Timur, Tengah dan Barat danau Sentani. Hasil penelitian menunjukkan parameter lingkungan perairan pada wilayah Timur dan Tengah danau Sentani yaitu distrik Puay dan Asei kecil masih layak untuk pengembangan budidaya Karamba Jaring Apung, berbeda pada wilayah Barat di sekitar Simporo beberapa parameter lingkungan budidaya menunjukkan kurang layak. Faktor Internal dan eksternal dengan cara peningkatkan pemahaman kelompok budidaya akan pentingnya pemanfaatan sumberdaya danau berpengaruh terhadap pengembangan budidaya karamba jaring apung di danau Sentani. Penguatan sinergitas antara pembudidaya dan kolaboratif dengan berbagai pihak merupakan strategi yang tepat untuk mendorong peningkatan pendapatan dan kesejahteraan pembudidaya
\end{abstract}

Kata Kunci : Lingkungan, Internal dan eksternal Budidaya Ikan Danau Sentani

\section{ABSTRACT}

This study aims to analyze the internal and external environment that affect the development of fish culture and assess the right strategy in the development of floating net cage fish farming in Sentani Lake Jayapura, carried out for three months from June to August 2019. The method is carried out by survey techniques through In-depth observations and interviews with stakeholders consisting, beneficiary communities and relevant government, were analyzed by scoring and SWOT at nine different observation station points representing the East, Central and West areas of Lake Sentani. The results showed that the environmental parameters of the waters in the East and Central Sentani lakes, namely the districts of Puay and Asei small, were still suitable for the development of floating net Karamba cultivation, differing in the West region around Simporo, some parameters of the aquaculture environment showed that they were less feasible. Internal and external factors by increasing the understanding of aquaculture groups on the importance of the use of lake resources influence the development of floating net cage cultivation in Lake Sentani. Strengthening synergy between farmers and collaboratives with various parties is the right strategy to encourage farmers to increase income and welfare

Keywords: environment, internal and external of lake sentani fish culture

\section{PENDAHULUAN}

Danau ini terbentang antara Kota Jayapura dan Kabupaten Jayapura, Papua. memiliki luas 9.630 hektar (ha), sejauh ini merupakan sumber hidup bagi sekitar 5.000 keluarga di sekitarnya. Danau itu juga telah diprogramkan Pemerintah Kota Jayapura sebagai obyek wisata kota. Selain air hujan, Danau Sentani mendapatkan suplai air dari sekitar 34 sumber mata air dari pegunungan.

Danau Sentani sebagai ekosistem perairan tawar memiliki karakteristik parameter biofisik tertentu yang bervariasi berdasarkan waktu dan lokasi. Sebagai ekosistem perairan tawar sebagaimana ekosistem danau pada umumnya memiliki daya dukung ekologis dan ekonomis teruama dalam sector perikanan dan pariwisata. Parameter biofisik lingkungan sangat menentukan daya dukung terhadap produksi ikan baik dari sektor perikanan tangkap maupun budidaya. Khususnya dalam upaya pengembangan sektor budidaya kajian khusus yang menduga potensi budidaya dalam kaitannya dengan kesesuain secara ekologis berdasarkan parameter biofisik masih sangat jarang dilakukan. Mengantisipasi dampak negatif yang mungkin terjadi di Danau Sentani maka perlu system pengelolaan yang terencana dan terpadu sehingga sumberdaya alam dapat dimanfaatkan secara terpadu.

Berdasarkan latar belakang diatas, maka perlu adanya perumusan staretgi pengembangan budidaya karamba jaing apung yang berada di danau Sentani. Maka perlu kajian dengan tujuan menganalisis parameter lingkungan dan faktor internal eksternal untuk membuat strategi untuk pengembangan budidaya karamba jaring apung secara berkelanjutan diharapkan hasil kajian ini dapat menjadi sumber informasi penting untuk pengembangan sektor perikanan khususnya budidaya karamba jaring apung dalam rangka menentukan kebijakan yang tepat terhadap pengembangan danau Sentani yang berkelanjutan . 


\section{METODE PENELITIAN}

\section{Waktu Dan Tempat Penelitian}

Penelitian ini dilaksanakan pada bulan Juni hingga Agustus 2019 di daerah budidaya dengan menggunakan karamba Jaring Apung yang masih beroperasi di Danau Sentani Kabupaten Jayapura Papua.

\section{Metode Penarikan Sampel}

Metode yang digunakan dalam penelitian dengan data primer dan sekunder sebagaimana dalam uraian berikut :

a. Data Primer

Data primer merupakan sumber data penelitian yang diperoleh secara langsung dari sumber asli (tidak melalui perantara). Data primer secara khusus dikumpulkan oleh peneliti untuk menjawab pertanyaan penelitian (Indriantoro, 2009).

b. Data Sekunder.

Data sekunder diperoleh dari artikel yang telah dipublikasi maupun yang tidak dipublikasikan, arsip dan dokumentasi dari instansi pemerintah dan lembaga terkait, meliputi informasi yang terkait dengan daerah penelitian serta data lain yang dibutuhkan dalam penelitian.

\section{Teknik Pengumpulan Data}

Teknik pengumpulan data dalam penelitian ini dilakukan melalui:

- Wawancara, data yang diperoleh dengan melakukan Tanya jawab untuk mendapatkan data awal sebagai masukan untum penelitian selanjutnya.

- Kuesioner, data yang didapatkan melalui beberapa pertanyaan yang diberikan kepada petani budidaya rumput laut dalam bentuk tertulis Dan selanjutnya diberi snoring.

\section{Analisis Data}

a. Faktor-faktor internal dan eksternal yang didapatkan dari identifikasi yaitu faktor kekuatan, kelemahan, peluang dan ancaman kemudian dimasukkan ke dalam matrik SWOT untuk dianalisis. Analisis SWOT ini menggambarkan secara jelas peluang dan ancaman eksternal yang dihadapi pembudidaya, yang disesuaikan dengan kekuatan dan kelemahan yang dimiliki. Matrik ini akan menghasilkan 4 set kemungkinan strategi antara lain strategi SO, strategi ST, strategi WO, dan strategi WT.

b. Menyilangkan masing-masing faktor sehingga didapat strategi SO, ST, WO, dan strategi WT.

\section{HASIL DAN PEMBAHASAN}

Danau Sentani yang terletak di Wilayah Kabupaten Jayapura merupakan danau terbesar dan cukup subur yang berada di Provinsi Papua dengan luas perairan sekitar 9.360 ha dengan kedalaman sekitar 52 m dengan ketinggian dari permukaan danau 70 - 90 dpl. dengan perkiraan panjang maksimum membentang dari timur ke barat 28 kilometer (17 mil) dan, dari utara ke selatan, lebarnya 19 kilometer (12 mil). Dengan luas permukaan 104 kilometer persegi (40 mil persegi). Danau Sentani merupakan perairan yang semi terbuka, dimana kondisi perairan untuk kesesuaian budidaya air tawar di KJA dilakukan dengan memperhatikan karakteristik lingkungan dan kualitas air memperlihatkan karakteristik variatif dapat dikatakan tidak terlalu tinggi dan cenderung merata nilai parameter kualitas air untuk semua stasiun penelitian yang dilakukan di Asei kecil, Puay dan Simporo. Hasil pengumpulan data dari kelompok pembudidaya ikan karamba jaring apung serta stakeholder yang terkait dan dilakukan analisis pada faktor internal dan eksternal sebagai berikut

Tabel 1. Strategi Internal

\begin{tabular}{lccc}
\hline \multicolumn{1}{c}{ Strategi Internal } & Item & Rtg & juml \\
\hline Kekuatan & & & \\
Motivasi usaha KJA pencaharian utama & 0.105 & 4 & 0.421 \\
Petani memperoleh bibit berkualitas baik & 0.100 & 4 & 0.403 \\
Sumber tenaga kerja mudah dan murah & 0.110 & 4 & 0.445 \\
Pemasaran produk mudah & 0.103 & 3 & 0.311 \\
Potensi lahan budidaya yang masih luas & 0.102 & 3 & 0.307 \\
Pengembangan KJA berbagai metode & 0.103 & 3 & 0.311 \\
\hline Kelamahan & & & \\
Pengetahuan pembudidaya terbatas & 0.069 & 2 & 0.139 \\
Keterbatasan bibit seragam \& berkualitas & 0.071 & 2 & 0.142 \\
Permodalan & 0.073 & 4 & 0.296 \\
Tingkat pendidikan pembudidaya kja & 0.082 & 2 & 0.166 \\
Kelompok kurang bekerja maksimal & 0.073 & 1 & 0.074 \\
\hline Total & & & $\mathbf{3 . 0 1}$ \\
\hline
\end{tabular}

Tabel 2. Strategi Eksternal

\begin{tabular}{lccc}
\hline \multicolumn{1}{c}{ Strategi Eksternal } & Item & Rtg & Juml \\
\hline Peluang & & & \\
Potensi untuk KJA masih sangat luas & 0.079 & 4 & 0.316 \\
Dukungan dari pemerintah & 0.072 & 3 & 0.218 \\
Hasil produksi bisa bervariasi olahan & 0.070 & 3 & 0.211 \\
Permintaan ikan KJA meningkat & 0.072 & 2 & 0.145 \\
Kontribusi thd PAD & 0.072 & 2 & 0.149 \\
Peluang diversifikasi produk luas & 0.077 & 4 & 0.308 \\
Penggunaan teknologi sederhana & 0.075 & 4 & 0.303 \\
Pertumbuhan dan kebutuhan masyarakat & 0.059 & 4 & 0.238 \\
\hline Ancaman & & & \\
Penyakit jamur dan bakteri di KJA & 0.054 & 4 & 0.216 \\
Produksi ikan daerah lain & 0.054 & 3 & 0.162 \\
Perkembangan IPTEK sulit diikuti & 0.049 & 4 & 0.199 \\
Iklim dan cuaca tidak menentu & 0.057 & 4 & 0.229 \\
Kurangnya permintaan di daerah lain & 0.056 & 4 & 0.225 \\
Kebijakan pemerintah harga BBM & 0.066 & 3 & 0.198 \\
\hline Total & & & $\mathbf{0 . 3 6}$ \\
\hline
\end{tabular}

Strategi Pada Faktor SO (Kekuatan dan Peluang

Berdasarkan analisis faktor Kekuatan dan Peluang (SO) dalam strategi analisis pengembangan budidaya karamba jaring apung di danau Sentani, mengarah pada pemberdayaan pembudidaya karamba jaring apung melalui pelatihan dan bimbingan dalam meningkatkan pendapatan usaha budidaya ikan di karamba jaring apung. Disamping itu pemerintah dan petani harus saling mendukung pada penguatan sinergitas peningkatan kualitas bibit ikan baik dari dalam maupun luar wilayah.

\section{Strategi Pada Faktor ST (Kekuatan danAncaman)}

Berdasarkan analisis faktor Kekuatan dan Ancaman (ST) dalam strategi analisis pengembangan budidaya di Danau Sentani sebaiknya tertuju pada peningkatan pendapatan masyarakat, pemberdayaan melalui pelatihan dan berorientasi peningkatan dan diversifikasi usaha. Peran pemerintah harus lebih giat dalam menjaga kestabilan harga produk, membaca peluang dan potensi pasar dan mediasi pemerintah kepihak luar untuk menjaga kesetabilan distribusi hasil produksi ikan dari karamba jaring apung. 
Strategi Pada Faktor WO (Kelemahan dan Peluang) Berdasarkan analisis faktor Kekuatan dan Peluang (WO) peran pemerintah harus lebih giat dalam melaksanakan dan membuka forum diskusi dan sharing informasi kepada petani pembudidaya karamba jaring apung, juga harus giat mendorong inovasi dan pengetahuan yang mengarah pada penerapan teknologi kepada masyarakat melalui pelatihan dan kerjasama lintas instansi seperti dengan perguruan tinggi dan perbangkan dalam program kredit lunak bagi pembudidaya ikan.

\section{Strategi Pada Faktor WT (Kelemahan dan Ancaman)}

Berdasarkan analisis faktor Kekuatan dan Peluang (WT) pemerintah perlu menurunkan kelompok terdidik guna untuk mendamping para pembudidaya supaya mudah memperoleh pengetahuan dalam hal penyediaan bibit berkualitas baik dan seragam, mengetahui inovasi teknologi terkini dalam produksi ikan di KJA serta adanya validitas dan keabsahan data lapangan dengan data pemerintah.

\section{Strategi pengembangan}

Berdasarkan analisis kelayakan usaha dan bagaimana faktor internal dan eksternal mempengaruhi kegiatan perikanan di danau Sentani Kabupaten Jayapura, pencemaran limbah domestik merupakan atribut pada dimensi ekologi yang sangat berpengaruh terhadap kuantitas dan kualitas air serta status keberlanjutan Danau Sentani.

Aktivitas budidaya terutama KJA selain memberi dampak positif ternyata juga menimbulkan dampak negatif yang sangat berpengaruh terhadap status keberlanjutan Danau Mustafa, $d k k$ (2008) dan Dahuri (2003) Hal ini diduga karena limbah dengan jumlahnya yang sudah melebihi kapasitas kemudian terakumulasi secara masal. Bai, dkk (2006) mengatakan budidaya ikan dengan karamba di danau dalam kurun waktu lama akan mempengaruhi lingkungan ekologis yang berdampak pada volume air pasokan dari danau, penampungan air dan jumlah banjir yang bisa ditimbulkan. Bueno, $d k k$ (2017) mengatakan salah satu strategi penting dalam pengelolaan danau untuk berkelanjutan dapat dilakukan dengan mengadopsi manajemen penggunaan model hidrodinamik yang menghitung kapasitas angkut atau nutrisi dari badan air tertentu dan efek dari budidaya ikan.

Berg, dkk (1996) mengatakan danau merupakan tempat potensial untuk usaha perikanan yang berkelanjutan bila mengakomidir kepentingan ekonomi, sosial dan ekologis. Bai dkk (2006) menyimpulkan pembuatan peraturan dan perencanaan budidaya ikan dengan menggunakan KJA memberikan dampak positif untuk pengembangan budidaya ikan di danau secara berkelanjutan. Penyerapan tenaga kerja dalam sektor pemanfaatan Danau Sentani sangat tinggi, tidak hanya oleh masyarakat lokal, tetapi banyak masyarakat non lokal yang bermata pencaharian di perairan terutama yang memiliki modal besar.

Strategi pembuatan kebijakan untuk dapat menjaga status keberlanjutan dari dimensi ekonomi dengan mengarahkan pada pembatasan jumlah pembudidaya yang disesuaikan dengan daya dukung danau, mengutamakan penyerapan tenaga kerja lokal dan penciptaan lapangan kerja alternatif seperti usaha pengolahan pakan ikan, pengolahan perikanan pasca panen, kegiatan pariwisata sehingga tidak semua pekerja bertumpu pada sektor budidaya di perairan Danau. Gurung, $d k k$ (2005) mengatakan peningkatan kapasitas sumberdaya manusia yang mendiami danau dengan kombinasi partisipatif manajemen perikanan dan kearifan lokal memberikan nilai tambah pada peningkatan kesejahteraan masyarakat miskin. Selanjutnya dikatakan pengelolaan perikanan partisipatif akan sangat memberikan kontribusi dalam menjaga keseimbangan ekologis ekosistem perairan.

\section{KESIMPULAN}

Faktor internal dan eksternal yang yang berpengaruh terhadap pengembangan budidaya karamba jaring apung di danau Sentani Kabupaten Jayapura, adalah meningkatkan pemahaman kelompok budidaya akan pentingnya pemanfaatan sumberdaya danau khususnya budidaya ikan di karamba jaring Apung untuk meningkatkan pendapatan dan kesejahteraan.

Strategi yang tepat dalam usaha pengembangan budidaya karamba jaring apung di Danau Sentani Kabupaten Jayapura saat ini adalah penguatan sinergitas antara pembudidaya ikan dengan pemerintah dan kolaboratif berbagai pihak untuk mendorong peningkatan pendapatan di sektor budidaya karamba jaring apung

\section{DAFTAR PUSTAKA}

Astuti LP, A Warsa \& H Satria. 2009. Kualitas Air dan Kelimpahan Plankton di Danau Sentani, Kabupaten Jayapura. Jurnal Perikanan (J. Fish Sci.), 11(1):66-77.

BAI Xiuling, GU Xiaohong \& Yang Longyuan. 2006. Analyses on water quality and its protection in East Lake Taihu, Journal of Lake Sciences 2006-01 (Nanjing Institute of Geography and Limnology, Chinese Academy of Sciences, Nanjing 210008, P.R.China)

Banon, Suherman; Atmaja dan Nugroho, Duto. 2011.upaya-upaya pengelolaan sumber daya ikan yang berkelanjutan dimindonesia.

Barus, T. A. 2004. Pengantar Limnologi Studi Tentang Ekosistem Air Daratan. Medan: USU Press

Bueno, Guilherme Wolff, Bureau, Dominique, SkipperHorton, James Owen, Roubach, Rodrigo, Mattos, Flávia Tavares de, \& Bernal, Francisco Ernesto Moreno. 2017. Mathematical modeling for the management of the carrying capacity of aquaculture enterprises in lakes and reservoirs. Pesquisa Agropecuária Brasileira, 52(9), 695-706. https://doi.org/10.1590/s0100-204x2017000900001

Chairulwan Umar, Safran Makmur. 2006. Komposisi Jenis dan Hasil Tangkapan Ikan di Danau Sentani Papua. B I O D I V E R S I T A S ISSN: 1412-033X Volume 7, Nomor 4 Oktober 2006 Halaman: 349-353.

Charles, AT. 2001. Sustainable Fishery System. Blackwell Science Ltd. Oxford.

Daniel Jamua, Moses Bandab , Robert E.Heckyd., 2011. Challenges to sustainable management of the lakes of Malawi Journal of Great Lakes Research Volume 37, Supplement 1, Pages 3-14 
Erlania; rusmaedi; prasetio, anjang bangun dan haryadi, joni. 2008. Dampak Managemen Pakan Dari Kegiatan Budidaya Ikan Nila (Oreochromis Nilocitus) Di Keramba Jarring Apung Terhadap Kualitas Perairan Danau Maninjau.Pusat Riset Perikanan Budidaya

Erwina, Yuyun; Kurnia, Rahmat dan Yonvitner. 2015. Status Berkelanjutan Sumber Daya Perikanan Di Perairan Bengkulu.

FAO Fisheries Department. 2004. The state of world fisheries and aquaculture. FAO Rome, pp 153.

Gurung, T., Wagle, S., Bista, J., Joshi, P., Batajoo, R., Adhikari, P., \& Rai, A. (1). Participatory fisheries management for livelihood improvement of fishers in Phewa Lake, Pokhara, Nepal. Himalayan Journal of Sciences, 3(5), 47-52. https://doi.org/10.3126/hjs.v3i5.461

Halomoan, Hutajulu. 2011. Valuasi Ekonomi Danau Sentani Di Kabupaten Jayapura. ECOTROPHIC $\bullet 7$ (2) : 135 - 144. ISSN: 1907-5626

Håkan Berg, Petra Michélsen, Max Troell, Carl Folke, Nils Kautsky. 1996. Managing aquaculture for sustainability in tropical Lake Kariba, Zimbabwe, Journal Ecological Economiss Volume 18, Issue 2 August 1996 pages 141-159. https://doi.org/10.1016/0921-8009(96)00018-3

Kementerian PPN / Bappenas Direktorat Kelautan dan Perikanan. 2014. Kajian Strategi Keputusan Direktur Jendral Perikanan Nomor /KEP-DJPT/2014 Penilaian Indikator untuk Pengelolaan Perikanan dengan Pendekatan Ekosistem (Ecosystem Approach to Fisheries Managem"

Mohammad Fauzi, Rispiningtati, Andre Primantyo Hendrawan. 2014. Kajian Kemampuan Maksimum Danau Sentani Dalam Mereduksi Banjur Di Das Sentani. Jurnal Teknik Pengairan, Volume 5, Nomor 1, Mei 2014, hlm 42-53

Moore, j. m., A. Rocchi \& S. M Renyaan. 2005. The Background Of Lake Sentani. http://www.hannover.park.org/canada/museum/arcella /5ref.html. Tanggal 1 september 2005

Muhtadi, A., H. Wahyuningsih, N. Zaharuddin, dan A. Sihaloho. 2016. Status Kualitas Air dan Kesuburan Perairan Danau Kelapa Gading Kota Kisaran Provinsi Sumatra Utara. Prosiding Seminar Nasional USU ke64:131- 137.

Muhtadi , Ahmad. 2017. Pengelolaan Danau Di Indonesia. Profram studi pengelolaan sumberdaya perairan sekolah pascasarjana institute pertanian bogor.

Peraturan Pemerintah Republik Indonesia. 2001. Peraturan Pemerintah Republik Indonesia Nomor 82 Tahun 2001 tentang Pengelolaan Kualitas Air dan Pengendalian Pencemaran Air. Kementrian Lingkungan Hidup. Jakarta.

Purwaningsih, Ratna; Santosa, Haryo. 2015. Pengembangan Metode Penilaian Keberlanjutan (Sustainability Assessment) Klaster Insdustri Perikanan. Prosiding SNST ke-6 Tahun 2015 Fakultas Teknik Universitas Wahid Hasyim Semarang

[PP] Peraturan Pemerintah Republik Indonesia Nomor 82 Tahun 2001. Pengelolaan Kualitas Air dan
Pengendalian Pencemaran Air. Sekretariar Negara RI. Jakarta.

Rasidi, Erlania, dan Prasetio, Anjang Bangun. 2009. Evaluasi Dan Status Perkembangan Usaha Budidaya Ikan Dalam Keramba Jarring Apung Di Danau Maninjau, Sumatra Selatan. Pusat Riset Perikanan Budidaya

Salmin. 2005. Oksigen terlarut (DO) dan kebutuhan oksigen biologi (BOD)sebagai salah satu indikator untuk menentukan kualitas perairan Oseana, Volume XXX, Nomor 3, 2005 : 21 26.www.oseanografi.lipi.go.id/volxxxno33.pdf. (28.03.2012)

Shibani Rosyshree Mishra and Amy L.Griffin. 2010. Encroachment: A threat to resource sustainability in Chilika Lake, India Journal Applied Geography Volume 30, Issue 3, Pages 448-459

Shi Weigang; WANG Bo; ZHOU Xin. 1999. Effects of Pen Fish and Crab Polyculture on Burden of Nitrogen and Phosphorus in Aquatic Environment of Weedtype Lakes, Journal of lake science vol 4 (Freshwater Fisheries Research Center of CAFS,)

Soeprobowati, T. R., W. H. Rahmanto, Jafron W. Hidayat. 2005. Kajian Perubahan Lingkungan Ekosistem Lentik Danau Rawa Pening Menggunakan Diatom sebagaiBioindikator. Laporan akhir hasil penelitian hibahbersaing. Kerjasama Universitas diponegoro - DitjenPendidikan Tinggi, Depdiknas. $12 \mathrm{p}$.

Sondita, Dr. Ir. M. Fedi A., M.Sc. 2011. Modul 1 Pengertian Manajemen dan Alasan Mengapa Sumber Daya Perikanan Perlu Dikelola.

Wibowo, Arif Budi, et. al. 2015. status berkelanjutan dimensi ekologi dalam pengembangan kawasan minapolitan berkelanjutan berbasis perikanan. 